\title{
Student Understanding of Number Line Graphs
}

\section{Alison C. Mirin}

School of Mathematical and Statistical Science, Arizona State University, USA.

\begin{abstract}
This paper addresses how students understand number line graphs. Utilizing a Think Aloud interview followed by a reflection-eliciting interview, we investigate how two successful College Algebra students understand what it means to graph a statement with one free variable on a number line. These particular students show a mathematically non-normative understanding of this concept; to wit, they do not view the number line graph as representing a solution set. This study illustrates the importance of future research into how students understand the concept of solution representation via number line graphs.
\end{abstract}

Keywords: college algebra; number line; graph; solution set. 


\section{Introduction and Literature Review}

When studying intermediate algebra, students often graph inequalities on number lines. A student asked to graph " $2 \mathrm{x}-3>5$ " on a number line often begins by employing a computatation, expressed as a series of equivalent statements: " $2 x>8$ ", followed by " $x>4$ ". Aided by " $x>4$ ", the student would then label " 4 " on the number line, mark an open dot on it, and shade everything to the right of that open dot. Their resulting number line plot is correct because it displays all of the numbers that, when substituted for " $x$ " in " $2 x-3>5$ ", make that inequality true. This is consistent with the United States Common Core Standards, which explain that a student as early as grade six (ages 10-12) should "recognize that inequalities of the form $\mathrm{x}>\mathrm{c}$ or $\mathrm{x}<\mathrm{c}$ have infinitely many solutions and represent solutions of such inequalities on number line diagrams" (National Governors Association, 2010).

The idea of number line graphs as representing solution sets is not limited to inequalities; any statement about real numbers in one free variable, say $\mathrm{P}(\mathrm{x})$, can be thought of as representing the solution set $\{\mathrm{x}$ : $\mathrm{x}$ is a real number and $\mathrm{P}(\mathrm{x})$ is true $\}$. For example, the number line graph of the statement " $|\mathrm{x}-2|=6$ " includes closed circles at precisely 8 and -4 . The idea of number line graphing is closely related to the idea of "solving for $\mathrm{x}$ ". When we "solve for $\mathrm{x}$ " in, say, " $|\mathrm{x}-2|=6$ ", we write something like " $\mathrm{x}=-4,8$ "; that is, we describe the solution set of the inequality similarly to how we would graph the solution set on a number line. Because describing solution sets covers a large portion of algebra curriculum (see, for example, Miller and Gerken, 2016), it is important to understand how students approach this task and remedy misunderstandings. Some work has indicated that students do not understand "solving for x" as involving solution sets (Frost, 2015). This paper expands that work by addressing the visual analogue, which is how students understand number line graphs, which we (the mathematical community) understand as representing solution sets. That is, this study considers the following questions: 1) What do students think it means to graph a statement (with one free variable) on a number line?, and 2) How do students see the graph of a number line as relating to the idea of solution set?

There appears to be a dearth of literature on how students understand number line graphs of statements in one free variable. However, there is some literature on how students understand solution procedures of statements in one free variable that may be graphed on number lines. Almog and Ilany (2012) found that high school students erred in solving absolute value inequalities, frequently misusing logical connectives such as "and" and "or". Sfard and Linchevski (1994) report on a similar phenomenon, in which high school students answered that " $x_{1,2}>3,-2$ " is a solution to " $\mathrm{x}^{2}-\mathrm{x}-6>0$ " but could not (i.e. did not, despite probing from an interviewer) explain further what that answer means. Additional research supports the idea that students, including pre-service teachers, struggle to interpret the results of manipulating equation and inequalities (Bicer et al., 2014; Blanco \& Garrote, 2007; El-khateeb, 2016) Specifically, Bicer et al. (2014) find that pre-service teachers often incorrectly represent their 
solution on the number line. It seems reasonable to think that such students might have a mathematically non-normative understanding of what it means to graph something on a number line. These students may not understand a number line graph as representing a solution set.

It bears mentioning that I am not using the word "set" in "solution set" in a formal, settheoretic sense. There are multiple mathematically normative ways that a student could conceive of a number line graph of a statement $\mathrm{P}(x)$. One is in the more formal, static way; the number line graph simply represents the set of real numbers that make $\mathrm{P}(x)$ true. Another is a more dynamic way in which a student might view a number line graph of a statement $\mathrm{P}(x)$ as the result of an infinite process of plugging in each real number $x$. That is, a student might view a number line graph as representing a record of plugging in individual values of $x$, checking for truth of $\mathrm{P}(x)$, and then marking $x$ on the number line if $\mathrm{P}(x)$ is true. In this study, I investigate if students view a number line graph of a statement $\mathrm{P}(x)$ as correct when the graph displays precisely the values of $x$ that make $\mathrm{P}(x)$ true.

\section{Methodology and Theoretical Perspective}

Data were collected via individual interviews. I adapted a two-interview structure from KoroLjungberg et al. (2013) in which the first interview (for each student) begins with a simple, non-mathematical warm-up activity to get the student comfortable verbalizing their thoughts. It continues with a Think Aloud (TA), during which the student narrates their thoughts while solving problems. I later conducted a separate in-depth and loosely-structured interview (cf. Ginsburg (1981)) which enabled me to probe students on their thinking and elicit reflections.

I am guided by a pragmatist perspective similar to that of Pierce and adopted by constructivists in math education (Clement, 2000; Crotty, 1998). This perspective views the thoughts and mathematical meanings of a student as inaccessible to direct observation. To overcome this inaccessibility, student thought is constructed through models that are consistent with their behavior. As described in Clement (2000), individual student interviews are consistent with constructivism in that they provide data (student responses) for building explanatory models of student thought (student meanings that account for such responses). Since there has yet to be research on how students understand number line graphs, this study is intended to be expoloratory and aimed at discovering student mental structure (Ginsburg, 1981). 


\section{Subjects and Methods}

The participants, Sara and Hannah, were enrolled in College Algebra at Anonymous State University (ASU). They were recruited via a mass email by their instructor and chosen because they were the first to contact the recruiter. They were compensated with a $\$ 30$ Amazon gift card. Both students were earning an A in the course. Sara was in her late 20's, held an undergraduate degree, and had returned to college to earn a second undergraduate degree in Computer Science. Hannah was 19 years old and studying to be an elementary math teacher. She had taken introductory calculus twice.

Their College Algebra course was administered entirely online. The course utilized ALEKS (Assessing and LEarning in Knowledge Spaces), a McGraw-Hill adaptive learning and assessment system (Aleks.com, 2019). The mathematical meanings that students have and construct in this course have yet to be studied.

I conducted the interviews privately, in my office. The interviews were performed a week apart starting at the end of Spring 2019. During the interviews, the students answered questions, worked on a computer within the ALEKS learning environment, and worked on an iPad. The computer and iPad screens were recorded with audio. The first part of the TA included standard, routine problems within the ALEKS environment (see Fig. 1). These included linear inequality solving and graphing, as well as problems solving absolute value equations. Due to the close relationship between solving for $\mathrm{x}$ and graphing on a number line, "solve for x" type problems were included.

\begin{tabular}{|l|l|}
\hline (A) Solve for $w$ in $3<13-5 w$ & (B) Solve for $x$ in $|4 x-8|=-4$ \\
\hline (C) Graph $3<13-5 w$ on a number line & (D) Solve for $v$ in $|6 v+18|=12$. \\
\hline
\end{tabular}

Figure 1. Standard problems, which were included in the Think Aloud (TA). A, B, and D were administered online in the ALEKS environment, whereas $C$ was not..

The TA was intended to reveal how the students approached such problems on their own. The TA ended with nonstandard problems (see Fig. 2), outside the ALEKS environment. These problems were sequenced at the end of the TA, as their nonstandardness had the potential to trigger reflection with which the student might not typically engage.

\begin{tabular}{l} 
(5) $\begin{array}{l}\text { Graph }|6 v+18|=12 \text { on a } \\
\text { number line. }\end{array}$ \\
\hline
\end{tabular}

Figure 2. Nonstandard problems included at end of the Think Aloud and revisited during the Follow-Up interview. 
The purpose of the more routine problems was to see if students consciously thought of solution sets when engaging with the typical course problems; these problems could be solved by applying routine algorithms and hence did not necessitate thinking in terms of solution sets. The purpose of the nonroutine problems was to see if students thought of the number line as representing solution sets. While solving absolute value equations is included in the curriculum, graphing them on number lines is not (hence the inclusion of Problem E as a nonstandard problem).

If a student understands a number line graph as representing a truth set, then Problem $\mathrm{F}^{1}$ should not be diffulct. The student need only observe that, for example, -2 makes the inequality true but is not shaded in the number line. Probing questions were included in the interview protocol for students who struggled with these problems. In particular, for Problem $\mathrm{F}$, if students did not think to plug in a value of $\mathrm{x}$, I prompted them to plug in a value of $\mathrm{x}$ that was inconsistent with the provided number line graph.

\section{Results}

Both students approached the problems procedurally, and neither of them appeared to view the number line as representing a solution set. Sara's meaning for "graph $\mathrm{P}(\mathrm{x})$ on a number line" appeared to be as follows: get $x$ by itself by performing symbol manipulation, and graph what she calls "the result". For her, the "result" is as follows: something of the form " $x>a$ " meant to shade everything greater than $a$, and something of the form " $x=a, b$ " meant to shade (put closed circles on) both $a$ and $b$. Hannah's meaning appeared to be as follows: perform symbol manipulation to get $x$ by itself. The result involves some sort of critical numbers (in Hannah's words, "what $x$ is"); if the result is something of the form " $x>a$ ", then a is a critical number, and if the result is something of the form " $x=a, b$ " then $a$ and $b$ are critical numbers. Mark the critical numbers on the number line, resulting in a segmented number line. For each segment of the number line, choose a number $c$ in that segment and assess the truthvalue of $P(c)$. If $P(c)$ is true, shade the portion of the number line where $c$ is. I refer to these as their meanings ("Sarah's meaning", and "Hannah's meaning") for graphing a statement on a number line and illustrate how these meanings manifested themselves in the interviews.

Hannah and Sara performed similarly on the standard problems (see Fig. 1). They followed the procedures that they had learned in ALEKS to arrive at answers. Both students made a mistake in solving Problem B (solving for $\mathrm{x}$ in $|4 \mathrm{x}-8|=-4$ ); they wrote both " $4 \mathrm{x}-8=-4$ " and " $4 \mathrm{x}-8=4$ ", then entered the results of solving those individual equations as their answer. This procedural focus suggests that neither student was approaching these routine problems with solution sets in mind. However, Sara and Hannah's differing responses when learning that

\footnotetext{
${ }^{1}$ Due to interviewer error, Sara received a slightly modified version of Problem F: see Fig. 3.
} 
their answers to Problem B (solving for $\mathrm{x}$ in $|4 \mathrm{x}-8|=-4$ ) were wrong illustrate differing understandings. Sara clicked on ALEKS' explanation, which asserted that all problems of the form $|f(x)|=c$ where $c$ is negative have no solutions, and accepted that her answer was wrong because this problem fit that form. Hannah, on the other hand, plugged in a value of $x$ that she found and then assessed the truth value of the equation with that value of $x$. While calculating each side of the equation, Hannah realized that anything she plugged in would make the equation false and concluded that it therefore had no solutions. This reaction suggests that Hannah, unlike Sarah, viewed the "solve" task to be about finding values that make the statement true.

Despite Hannah's eventual success on Problem B, her attempts to graph Problem E indicates that she did not view a number line graph as representing a truth set. In Problem D, she correctly solved for $v$ in the equation $|6 v+18|=12$. This fact, together with her eventual performance on $B$, suggests that she viewed her resulting values of $v$ to be members of a truth set. Therefore, if she thought of a number line graph as representing a truth set, providing the graph would have been a trivial task; just plot -5 and -1. Instead, Hannah got stuck when her meaning for "graph $\mathrm{P}(\mathrm{v})$ on a number line" (described above) did not yield a result for her. After plotting -5 and -1 on the number line, she proceeded to plug numbers into the original equation and check for truth or falsity.

Hannah's performance on these problems suggests that she did not understand a number line graph as representing a truth set; in Problem B, she seemed to understand a solution to an absolute value equation as representing a truth set, but her response to Problem E suggests that she did not always understand this concept. Sarah's response to Problem E was not particularly revealing, yet it was consistent with her meaning for "graph $\mathrm{P}(\mathrm{v})$ on a number line"; having written the correct solutions for Problem D (see Fig. 1), Sara correctly put solid dots on the number line at -5 and -1 . Sara did not mention the idea of solution sets or truth and plotted her solutions.

Student responses to Task F (see Fig. 2) were especially revealing. Both students immediately tried to solve the inequality on their own and only stopped when I told them that they would be unable to. Sarah did not think to plug in a number on her own, so I prompted her to plug in $x=0$. The fact that 0 made the inequality true but was not shaded on the number line was irrelevant to Sarah. Instead, she was preoccupied with figuring out where the hypothetical student got the -2 from in order to be able to evaluate his accuracy (see Fig. 3). 


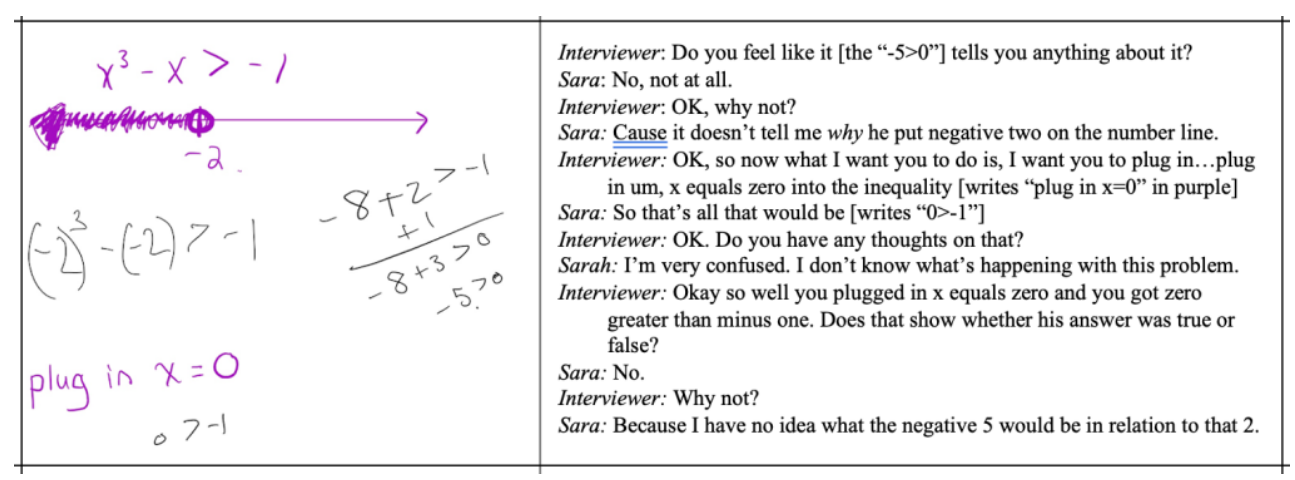

Figure 3. Sara's Responses to Problem F, Follow-Up Interview

Hannah's response to Problem F was more involved. She began plugging in values of $\mathrm{x}$ on her own. She first plugged in -2 and assessed the resulting statement as true. However, she did not know what to do with that information. The fact that -2 was not shaded on the number line yet made the inequality true did not indicate to her that the number line graph was incorrect. Yet, plugging in $\mathrm{x}=-1$ and getting a false statement, together with the fact that the -1 was not shaded, did tell her that the graph was incorrect (see Fig. 4). At face value, this is evidence that Hannah might be viewing this number line graph as representing a solution set. However, a closer look indicates that Hannah was considering a segmentation procedure for critical values of $x$. Instead of discussing the idea of solution set, she continued to focus on the segmentation of the number line by fixating on whether "it [a critical value] is -2 ". She considered the possibility that the hypothetical student should have graphed the portion of the number line right of -2 . The fact that -2 would be unshaded in such a graph, yet made the inequality true, was irrelevant to her; the critical values are not where she checked for truth, only the in-between points on each segment of the number line. Again, her meaning was to find the critical values, segment the number line, and test values within each segment. 


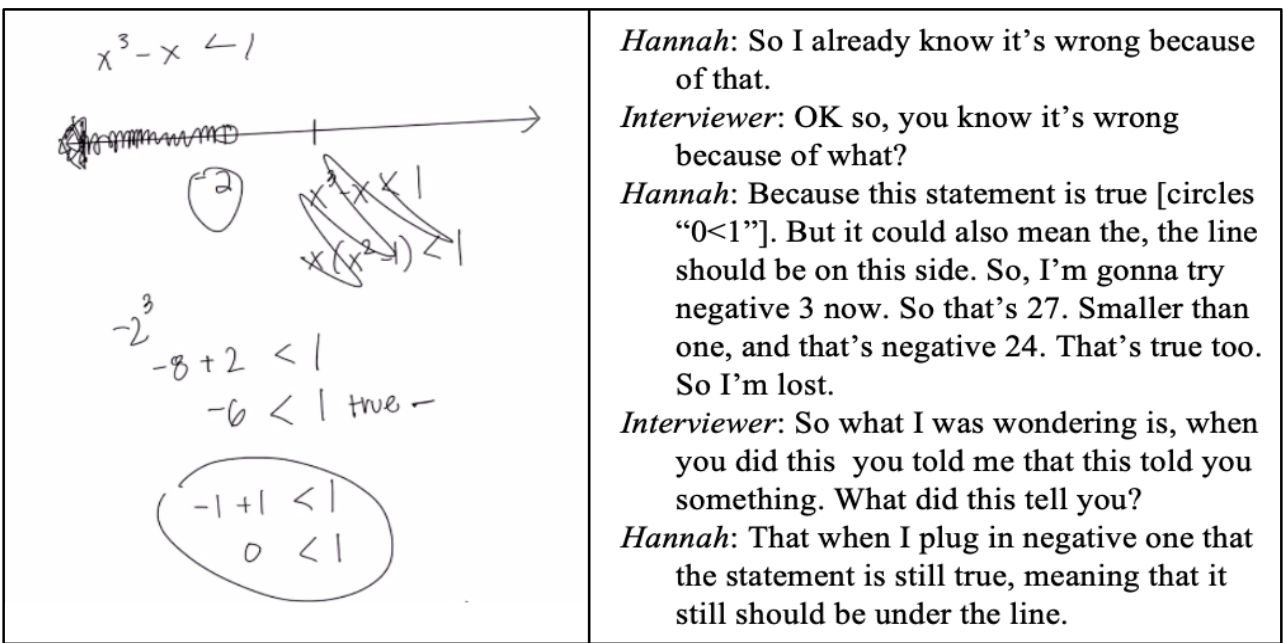

Figure 4. Hannah's responses to (modified) Problem F, Think-Aloud

\section{Discussion}

This data suggest that, like the command "solve for x", students might not view "graph on the number line" as a task about representing solution sets. This is despite both students performing well in the standard course problems. The good news is that both students, at the very end of the interview, appeared to improve their understanding of number line graphs as solution sets. This suggests that the mere act of reflection and exposure to nonstandard problems might have prompted the students to develop stronger meanings. Of course, future study is needed to further explore this hypothesis.

\section{References}

ALEKS -- Assessment and Learning, K-12, Higher Education, Automated Tutor, Math. (2019). Retrieved from https://www.aleks.com

Almog, N., \& Ilany, B.-S. (2012). Absolute value inequalities: High school students' solutions and misconceptions. Educational Studies in Mathematics, 81(3), 347-364. https://doi.org/10.1007/s10649-012-9404-Z

Bicer, A., Capraro, R., \& Capraro, M. (2014). Pre-service Teachers' Linear and Quadratic Inequalities Understandings. International Journal for Mathematics Teaching \& Learning.

Blanco, L. J., \& Garrote, M. (2007). Difficulties in Learning Inequalitiesin Students of the First Year ofPre-University Education in Spain. Eurasia Journal of Mathematics, Science and Technology Education, 3(3), 221-229. https://doi.org/10.12973/ejmste/75401

Clement, J. (2000). Analysis of clinical interviews: Foundations and model viability. Handbook of Research Design in Mathematics and Science Education, 547-589. 
Crotty, M. (1998). The Foundations of Social Research: Meaning and Perspective in the Research Process. SAGE. https://market.android.com/details?id=book-Op_SDKrf1ZQC

El-khateeb, M. (2016). Errors Analysis of Solving Linear Inequalities among the Preparatory Year Students at King Saud University. Journal of Education and Practice, 7(12).

Frost, J. (2015). Disappearing x: When solving does not mean finding the solution set. The Journal of Mathematical Behavior, 37, 1-17. https://doi.org/10.1016/j.jmathb.2014.10.003

Ginsburg, H. (1981). The Clinical Interview in Psychological Research on Mathematical Thinking: Aims, Rationales, Techniques. For the Learning of Mathematics, 1(3), 4-11.

Koro-Ljungberg, M., Douglas, E. P., Therriault, D., Malcolm, Z., \& McNeill, N. (2013). Reconceptualizing and decentering think-aloud methodology in qualitative research. Qual. Res., 13(6), 735-753. https://doi.org/10.1177/1468794112455040

Miller, J., \& Gerken, D. (2016). College Algebra. McGraw-Hill Education. https://market.android.com/details?id=book-wZW_oQEACAAJ

National Governors Association. (2010). Common Core State Standards for Mathematics. http://www.corestandards.org/Math/Content/8/F/

Sfard, A., \& Linchevski, L. (1994). Between Arithmetic and Algebra: In the Search of a Missing Link, the Case of Equations and Inequalities. Rendiconti Del Seminario Matematico Università e Politecnico Di Torino, 52(3), 279-307. 